\title{
Persistence in trends and cycles of gold and silver prices: Evidence from historical data
}

\author{
Juncal Cunado ${ }^{a}{ }^{*}$, Luis A. Gil-Alana ${ }^{a}$ and Rangan Gupta ${ }^{b}$ \\ ${ }^{a}$ University of Navarra, School of Economics, Edificio Amigos, E-31080 Pamplona, Spain \\ $\mathrm{b}$ Department of Economics, University of Pretoria, Pretoria, 0002, South Africa \\ * Corresponding author. \\ E-mail addresses: jcunado@unav.es (J.Cunado), alana@unav.es (L.A. Gil-Alana),rangan.gupta@up.ac.za (R. Gupta).
}

\section{Highlights}

- Persistence in gold and silver prices is analyzed in a fractional integration basis.

- Two parameters for the long run trend and the cyclical behavior are estimated.

- Only when the cyclical component is considered, mean reversion is detected.

- Cycles have a higher periodicity for gold than for silver prices.

\begin{abstract}
This study examines the persistence in gold and silver prices covering the historical periods of 1257 to 2016 and 1687 to 2016 respectively, by means of simultaneously estimating two differencing parameters for the long run trend and the cyclical behavior in a fractional integration framework. As opposed to many previous papers in the literature, once the cyclical differencing parameter is taken into account, mean reversion is detected in the long run trend of both gold and silver prices. The same result is obtained when structural breaks are taken into account. As far as the cyclical behavior of gold and silver prices is concerned, we find that cycles have a higher periodicity for gold (around 7 years) than for silver ( $4-5$ years).
\end{abstract}

Keywords:

Gold and silver prices; Persistence; Cyclical behavior; Fractional integration

\section{Introduction}

Although gold and silver prices have remained relatively flat and stable for centuries until the second half of the 20th century [1], they have been characterized, as the rest of the commodity prices, by a high volatility in the past two decades [2]. For example, gold and silver prices rose by $528 \%$ and by $806 \%$, respectively, from 2001 to 2011 (with only a $25 \%$ increase in overall inflation), and after reaching their maximum levels in 2011, they fell a 40\% and a 68\%, respectively, from 2011 to 2016. During the same two decades, gold and silver prices have shown a higher correlation with other commodity prices and stock prices [2-4]. These figures have raised different debates and questions in the economic literature that justify the interest of modeling the behavior of these two commodity prices. First, the increasing correlation of the prices of these two precious metals with stock prices could reduce the attractiveness of investments in gold or silver as a diversification and a hedging tool, raising the question of whether gold and silver have been or are safe havens [5-8], and whether they act as inflation hedges [9-11]. Additionally, the increasing trend in prices during the last decades raised the question of whether 
the gold and silver prices are driven by supply and demand factors or by speculation due to the so-called "financialization" of the commodities markets [2,3,12-14]. Moreover, since gold and silver represent a significant proportion of developing economies' exports ${ }^{1}[15]$ commodity price dynamics also constitute an economic growth and development factor in several developing countries, so that commodity price stability may constitute a policy objective to reduce poverty. Furthermore, the analysis of the degree of persistence of commodity prices relative to the prices of the manufactured goods is central to test the Prebisch-Singer hypothesis. ${ }^{2}$ Finally, central banks and governments hold gold as part of their reserves (according to the [18], gold is the third most popular asset in the advanced countries accounting for $20 \%$ of the international reserves), making the price of this precious metal part of the central banks' policies.

Like any other goods, gold's and silver's prices are determined by supply and demand factors, although unlike other commodity prices, they have historically played, and still play, an important role as money, as an investment and as a store of value, and, thus, are driven by a great number of factors. According to the literature, gold and silver prices are driven by the US dollar [19], the exchange rates of other currencies [20,21], interest rates [22], inflation rates or expected inflation rates [9,10,23-26], equity and bond market returns [27], the prices of other commodities [28-30], investor sentiment [31,32], economic cycles [31], or economic and policy uncertainty [26,33-35], among others. For example, Lau et al. [4] analyze the relationship between white precious metals, gold, oil and global equity by means of analyzing return spillovers and volatility transmission, and find that all these markets are well integrated.

Determining whether the impacts of all the above factors on gold and silver prices are temporary or permanent will depend on the time series properties of gold and silver prices. For example, if gold and silver prices are stationary, shocks will only have transitory effects on these variables, while if they are non-stationary, shocks will have permanent effects on them. Furthermore, the order of integration of these variables will determine whether or not these variables might be cointegrated with other variables [10], such as inflation, stock returns or interest rates. Additionally, if gold and silver were perfect inflation hedges, the real price of gold and silver would be stationary [10]. However, despite the vast literature directed to estimate the integration order or persistence of these variables [10,16,36-42] the results are not yet conclusive (see, for example, [41], for a recent survey of the literature). For example, Ghoshray [16] reexamines the Prebisch-Singer hypothesis, employing the unit root tests proposed by Lee and Strazicich [43,44] with one and two structural breaks and the results suggest the existence of unit roots in many commodity prices, including gold and silver. Narayan and Liu [36], for example, analyze whether shocks to ten commodity prices are persistent or transitory using two recently developed unit root tests (Narayan and Popp test and the Liu and Narayan test) allowing for structural breaks and they also conclude that gold and silver prices are non-stationary. However, Gil-Alana et al. [39] use monthly data from 1972:1 to 2013:13 and fractional integration techniques, and they find that real gold price is non-mean reverting while real silver price is mean reverting, concluding that in the event of exogenous shocks, the effects will be permanent in gold prices, although temporary in silver prices. Gil-Alana et al. [40] use annual data spanning from 1833 to 2013 for gold and 1792 to 2013 for silver and they find fractional order of integration above 1 in case of gold and below 1 for silver, concluding again that gold prices exhibit a non mean-reverting behavior, while they find mean reversion in silver prices. Winkelried [42] reexamines the Prebisch-Singer hypothesis testing for unit roots in commodity prices and find evidence against nonstationarity in at least 20 out of 24 cases, including gold and silver prices. Earlier attempts in this regard, can be found in [45-47], which in turn provides support for the Prebisch-Singer hypothesis.

In this context, the objective of the paper is to analyze the persistence in the trend and cyclical components of gold and silver prices using long spans of data, covering 1257 to 2016 and 1687 to 2016 respectively, within a fractional integration framework and allowing for two differencing parameters for the long run trend and cyclical behavior of these prices. The main contributions of the paper are the following. First, we use a long span of data that covers more than seven centuries for gold and more than three centuries for silver prices, a time period which includes many historical episodes that significantly impacted oil and silver prices, such as: the adoption of the gold standard, the Great Depression and the stock market crash in 1929, World Wars I and II, the Bretton Woods accord in 1944, the end of the gold standard, the oil price shocks in the 70s, the Lehman Brothers collapse and the Eurozone debt crisis, among others. Second, in a fractional integration framework, we use a model that incorporates simultaneously two fractional differencing parameters, one at the long run or zero frequency and another one at a cyclical frequency. Although a rather similar methodology has already been used in [40], in this paper we use a longer time period that allows us to more precisely estimate the two fractional differencing parameters and of the periods for the length of the cycles. In fact, in [40] the time period goes from 1833 (gold) and 1792 (silver) till 2013 while in this work the period examined is 1257-2016 for gold and 1687-2016 for silver. Moreover, we provide in this paper a more exhaustive analysis of the cyclical periodicity in the two series.

The rest of the paper is organized as follows: Section 2 presents the methodology, while Section 3 discusses the data and the empirical results. Finally, Section 4 concludes.

\footnotetext{
1 Note, for example, that gold is the leading export for several countries, such as Mali, Tanzania, Ghana or Guyana.

2 According to this hypothesis, the price of primary commodities declines relative to the manufactured goods over the long term. If this hypothesis holds, developing countries, with a higher export dependence on primary products, will lose out from a worsening of the terms of trade. See [16] and [17] for a survey of the literature.
} 


\section{Methodology}

We use in this paper techniques that are based on the concept of long memory or long range dependence. To be fairly general, we can provide two definitions of long memory. The time domain definition claims that a covariance stationary process $\left\{x_{\mathrm{t}}, t=0, \pm 1, \ldots\right\}$ displays the property of long memory if the infinite sum of the autocovariances tends to infinite. That is,

$$
\lim _{T \rightarrow \infty} \sum_{j=-T}^{T}\left|\gamma_{j}\right|=\infty .
$$

On the other hand, if we assume that $x_{t}$ has an absolutely continuous spectral distribution function, with a spectral density function given by:

$$
f(\lambda)=\frac{1}{2 \pi} \sum_{j=-\infty}^{\infty} \gamma_{j} \cos \lambda, \quad-\pi<\lambda \leq \pi,
$$

according to the frequency domain, we say that $x_{\mathrm{t}}$ displays long memory if its spectral density function is unbounded at some frequency $\lambda$ in the interval $[0, \pi]$, i.e.,

$$
f(\lambda) \rightarrow \infty, \text { as } \lambda \rightarrow \lambda^{*}, \quad \lambda^{*} \in[0, \pi],
$$

(see [48]). The empirical literature on long memory has focused mainly on the case when the singularity or pole in the spectrum takes place at the smallest (i.e., zero) frequency $(\lambda=0)$, i.e.,

$$
f(\lambda) \rightarrow \infty, \quad \text { as } \lambda \rightarrow 0^{+},
$$

and a very natural model satisfying the above two properties is the one based on the concept of fractional integration. We say that a process $\left\{x_{t}, t=0, \pm 1, \ldots\right\}$ is integrated of order $\mathrm{d}$, and denoted as $\mathrm{I}(\mathrm{d})$ if it can be represented as:

$$
(1-L)^{d} x_{t}=u_{t}, \quad t=0, \pm 1, \ldots,
$$

where $\mathrm{L}$ is the lag operator $\left(L x_{t}=x_{t-1}\right), \mathrm{d}$ can be any integer or fractional value and $u_{\mathrm{t}}$ is supposed to be $\mathrm{I}(0)$ defined for our purposes as a covariance stationary process (or a short memory process), where the infinite sum of the autocovariances is finite. Examples of $\mathrm{I}(0)$ processes are the white noise case and the stationary and invertible AutoRegressive Moving Average (ARMA) models.

However, the long memory processes may display other representations apart from the one given by (5). In fact, the singularity or pole might take place at any other frequency away from zero. This is the case of the model that is based on the following representation,

$$
\left(1-2 \cos \mu L+L^{2}\right)^{d} x_{t}=u_{t}, \quad t=1,2, \ldots,
$$

with

$$
\left(1-2 \mu L+L^{2}\right)^{-d}=\sum_{j=0}^{\infty} C_{j, d}(\mu) L^{j},
$$

where $C_{j, d}(\mu)$ are orthogonal Gegenbauer polynomial coefficients defined recursively as:

$$
\begin{aligned}
& C_{0, d}(\mu)=1, \quad C_{1, d}(\mu)=2 \mu d, \\
& C_{j, d}(\mu)=2 \mu\left(\frac{d-1}{j}+1\right) C_{j-1, d}(\mu)-\left(2 \frac{d-1}{j}+1\right) C_{j-2, d}(\mu), \quad j=2,3, \ldots,
\end{aligned}
$$

Gray et al. [49,50] showed that $x_{\mathrm{t}}$ in (6) is (covariance) stationary if $d<0.5$ for $\left|\mu=\cos w_{\mathrm{r}}\right|<1$ and if $d<0.25$ for $|\mu|=1$. This process implies the existence of a pole or singularity at a non-zero frequency which corresponds to the cyclical pattern. Special cases of this model were analyzed by Ahtola and Tiao [51,52] and Bierens [53,54] setting $d=1$, and by Gil-Alana [55], DePenya and Gil-Alana [56] and others allowing d to take fractional values.

In this paper we combine the two models given by Eqs. (5) and (6) in a single framework, that is, considering a model of form:

$$
(1-L)^{d_{1}}\left(1-2 \cos w_{r} L+L^{2}\right)^{d_{2}} x_{t}=u_{t}, \quad t=1,2, \ldots,
$$

where $d_{1}$ and $d_{2}$ are the integration orders corresponding respectively to the long-run and the cyclical frequency; $w_{\mathrm{r}}=2 \pi \mathrm{r} / \mathrm{T}$ with $\mathrm{r}=\mathrm{T} / \mathrm{j}$, $\mathrm{j}$ indicates the number of periods per cycle and $\mathrm{r}$ the frequency with a singularity or pole in the spectrum; and $u_{\mathrm{t}}$ is I $(0)$ process and potentially displaying weak autocorrelation of the ARMA-form.

We estimate the parameters in the model using the Whittle function in the frequency domain, as proposed in [57] and [58] among others. 


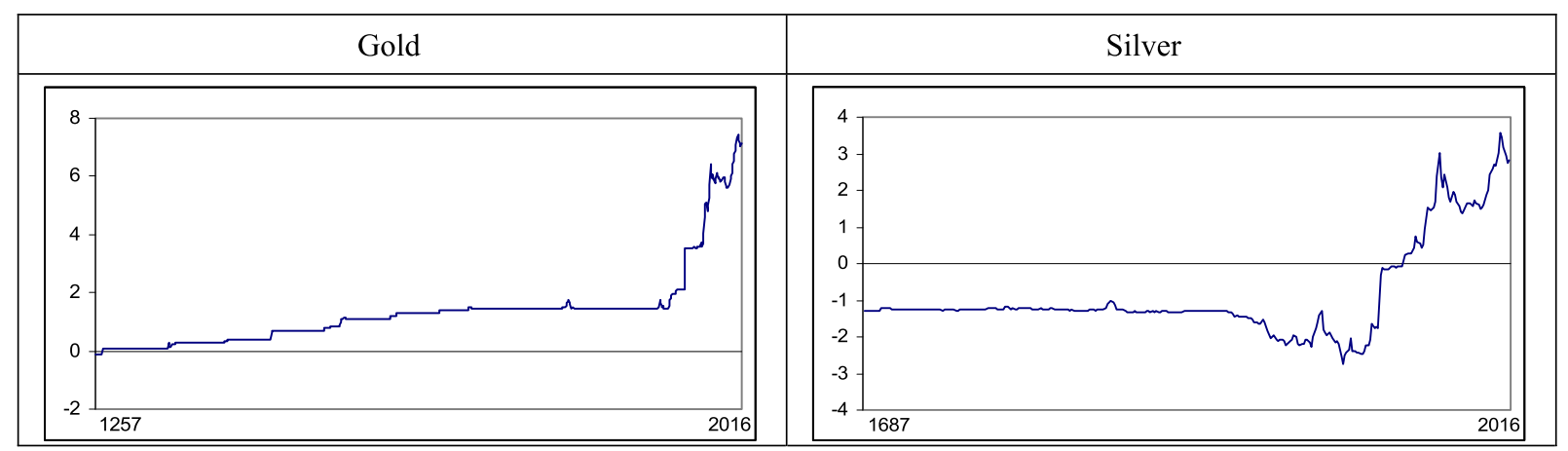

Fig. 1. Log-transformed data.

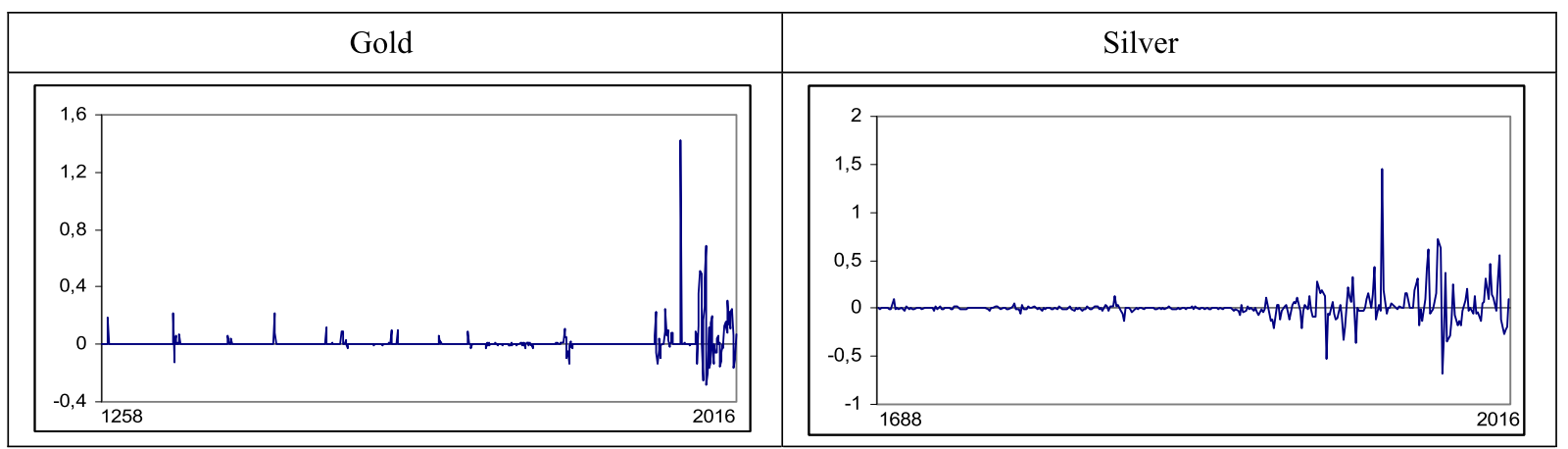

Fig. 2. First differenced data.

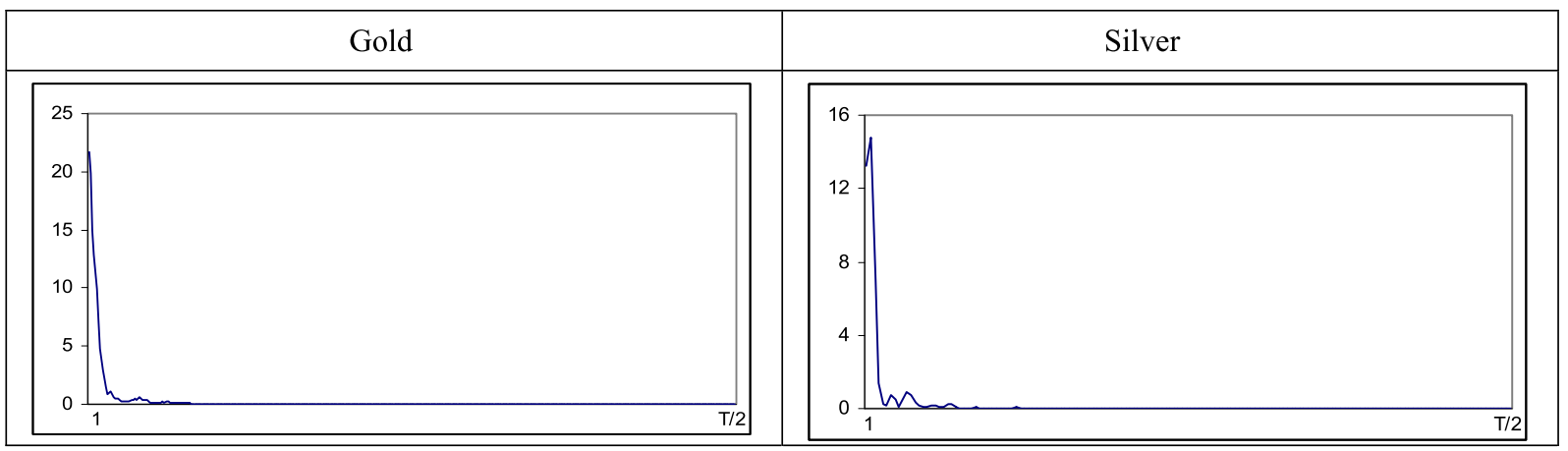

Fig. 3. Periodograms of the log-transformed data.

\section{Data and empirical results}

We use annual data for nominal prices (in British pounds) of gold over 1257 to 2016 and silver covering 1687 to 2016 retrieved from Measuring Worth (https://www.measuringworth.com). Data were transformed by taking natural logarithms.

Fig. 1 displays the time series plots (in logs) of gold and silver data, while Fig. 2 plots the first differenced data. The data on both these metal prices tends to remain fixed over yearly intervals in the early part of the sample, before increasing sharply from around 1940 for gold and 1946 for silver, i.e., during and after the World War II respectively. Tables 1 and 2 present summary statistics and test for normality and nonlinearity for the gold and silver prices (in logs) and their first differences. As reported in the tables, the null hypothesis of normality and linearity can be rejected for all the series.

Fig. 3 displays the periodograms of the two series and Fig. 4 displays the periodograms of the first differenced data. We observe that the highest values take place at the smallest frequency, suggesting thus a long memory model with the pole taking place at zero, i.e.,

$$
\mathrm{y}_{\mathrm{t}}=\beta_{0}+\beta_{1} t+x_{\mathrm{t}} ; \quad(1-L)^{d} x_{t}=u_{t}, \quad t=0,1, \ldots,
$$


Table 1

Summary statistics.

\begin{tabular}{|c|c|c|c|c|}
\hline \multirow[t]{2}{*}{ Statistic } & \multicolumn{4}{|l|}{ Variables } \\
\hline & $\overline{\text { LGOLD }}$ & RGOLD & LSILVER & RSILVER \\
\hline Mean & 1.3455 & 0.9549 & -0.8841 & 1.2605 \\
\hline Median & 1.3164 & 0.0000 & -1.2684 & 0.0000 \\
\hline Maximum & 7.4200 & 141.8796 & 3.5587 & 144.9503 \\
\hline Minimum & -0.1165 & -28.6355 & -2.7336 & -67.2759 \\
\hline Std. Dev. & 1.3716 & 7.8639 & 1.2848 & 15.0509 \\
\hline Skewness & 2.4584 & 9.6583 & 1.6718 & 3.2214 \\
\hline Kurtosis & 9.4427 & 151.7087 & 4.9760 & 32.3785 \\
\hline Jarque-Bera & 2079.9540 & 711164.4000 & 207.4108 & 12400.6600 \\
\hline Probability & 0.0000 & 0.0000 & 0.0000 & 0.0000 \\
\hline Observations & 760 & 759 & 330 & 329 \\
\hline
\end{tabular}

Note: LGOLD (LSILVER) is the natural logarithm of gold (silver) prices, and RGOLD (RSILVER) is the log-returns of gold (silver); Std. Dev. stands for standard deviation, while probability is the $p$-value for the Jarque-Bera test, with the null hypothesis of normality.

Table 2

(Brock et al. [59], BDS) test of nonlinearity.

\begin{tabular}{llllll}
\hline Independent variable & $m$ & \multicolumn{5}{l}{} \\
\cline { 2 - 6 } & 2 & 3 & 4 & 5 & 6 \\
\hline LGOLD & $53.3668^{* * *}$ & $56.8806^{* * *}$ & $61.3552^{* * *}$ & $67.8966^{* * *}$ & $76.8812^{* * *}$ \\
RGOLD & $18.3219^{* * *}$ & $19.6147^{* * *}$ & $21.0147^{* * *}$ & $22.5937^{* * *}$ & $24.4162^{* * *}$ \\
LSILVER & $41.3295^{* * *}$ & $43.6979^{* * *}$ & $46.8093^{* * *}$ & $51.4529^{* * * *}$ & $57.8144^{* * *}$ \\
RSILVER & $9.9636^{* * *}$ & $10.9289^{* * *}$ & $11.8325^{* * *}$ & $13.5624^{* * *}$ & $15.6200^{* * *}$
\end{tabular}

Note: Entries correspond to the $z$-statistic of the BDS test with the null of i.i.d. residuals, with the test applied to the residuals recovered from the LGOLD (LSILVER) equation with a constant and a trend, and RGOLD (RSILVER) with a constant.

${ }^{* * *}$ Indicates rejection of the null hypothesis at 1 percent level of significance.

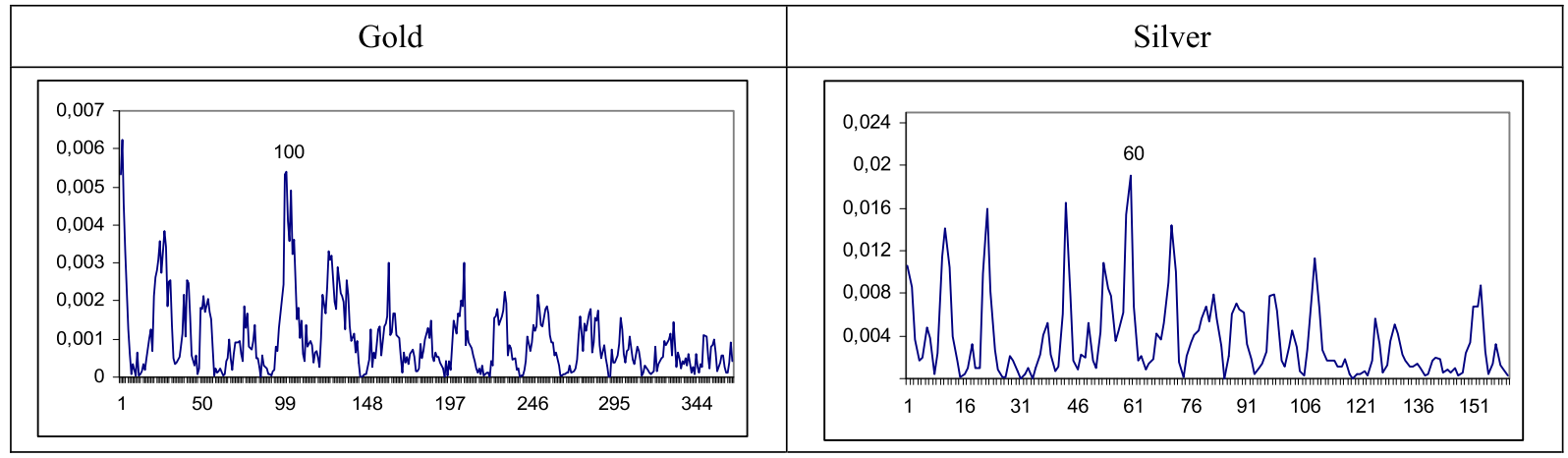

Fig. 4. Periodograms of the first differenced data.

where $y_{\mathrm{t}}$ is the observed data ( $\log$ of gold and silver prices); $\beta_{0}$ and $\beta_{1}$ are unknown coefficients referring respectively to the intercept and the time trend. We estimate $d$ in this context under two different modeling assumptions. First, considering that $u_{\mathrm{t}}$ is an uncorrelated (white noise) process, and then imposing autocorrelation for the error term. ${ }^{3}$ The results are reported in Table 3.

We report in Table 3 the fractional differencing parameter $\mathrm{d}$ for the three standard cases examined in the literature, i.e., the case of no deterministic terms (i.e., $\beta_{0}=\beta_{1}=0$ a priori in the undifferenced equation (8), including only a constant ( $\beta_{0}$ unknown, and $\beta_{1}=0$ a priori), and finally the case of a constant with a linear time trend ( $\beta_{0}$ and $\beta_{1}$ unknown). We marked in bold the selected model according to these deterministic specifications. It is observed that under no autocorrelation the time trend is not statistically significant and an intercept is sufficient to describe the deterministic terms. However, under autocorrelation the time trend is required in the two series. Focusing now on the degree of integration, the estimated values of $d$ are above 1 in the two series under no autocorrelation, but they are in the I(1) interval under Bloomfield (autocorrelated) disturbances. Performing several diagnostic tests they confirm that the autocorrelated case is more appropriate.

3 Here we use the exponential spectral model of Bloomfield [60] that approximates highly parameterized ARMA models with very few parameters. 
Table 3

Estimates of the long run persistence parameter.

\begin{tabular}{|c|c|c|c|}
\hline \multicolumn{4}{|c|}{ (i) No autocorrelation } \\
\hline Series & No terms & An intercept & A linear trend \\
\hline Gold & $\begin{array}{l}1.15 \\
(1.10,1.21)\end{array}$ & $\begin{array}{l}1.15 \\
(1.10,1.21) \\
\end{array}$ & $\begin{array}{l}1.15 \\
(1.10,1.21) \\
\end{array}$ \\
\hline Silver & $\begin{array}{l}1.07 \\
(1.10,1.16)\end{array}$ & $\begin{array}{l}1.09 \\
(1.02,1.19)\end{array}$ & $\begin{array}{l}1.09 \\
(1.02,1.19)\end{array}$ \\
\hline \multicolumn{4}{|c|}{ (i) With autocorrelation } \\
\hline Gold & $\begin{array}{l}1.05 \\
(0.99,1.11) \\
\end{array}$ & $\begin{array}{l}1.04 \\
(0.991 .10)\end{array}$ & $\begin{array}{ll}1.04 \\
(0.991 .10) \\
\end{array}$ \\
\hline Silver & $\begin{array}{l}0.97 \\
(0.89,1.09)\end{array}$ & $\begin{array}{l}0.94 \\
(0.88,1.04)\end{array}$ & $\begin{array}{l}0.95 \\
(0.86,1.05)\end{array}$ \\
\hline
\end{tabular}

Note: In bold the significant models according to the deterministic terms. In parenthesis, $95 \%$ confidence intervals of the estimated values of $d$.

Table 4

Estimated coefficients in Eq. (9).

\begin{tabular}{lll}
\hline (i) Original data & & \\
\hline Series & j & d \\
\hline Gold & 101 & $0.08(0.05,0.12)$ \\
Silver & 59 & $0.04(0.00,0.09)$ \\
\hline (i) Mean subtracted data & & \\
\hline Series & j & d \\
\hline Gold & 101 & $0.08(0.04,0.12)$ \\
Silver & 59 & $0.04(0.00,0.10)$ \\
\hline
\end{tabular}

Table 5

Estimated coefficients in the model given by (10) under white noise disturbances.

\begin{tabular}{llrl}
\hline (i) Original data & & & \\
\hline Series & $d_{1}$ & $\mathrm{j}$ & \multicolumn{1}{l}{$d_{2}$} \\
\hline Gold & $0.75(0.68,0.81)$ & 103 & $-0.19(-0.24,-0.10)$ \\
Silver & $0.90(0.83,0.98)$ & 69 & $-0.35(-0.39,-0.17)$ \\
\hline (ii) Mean subtracted data & \multicolumn{3}{l}{} \\
\hline Series & $d_{1}$ & \multicolumn{1}{l}{ j } & $d_{2}$ \\
\hline Gold & $0.73(0.66,0.80)$ & 101 & $-0.22(-0.29,-0.11)$ \\
Silver & $0.88(0.80,0.97)$ & 55 & $-0.31(-0.40,-0.21)$ \\
\hline
\end{tabular}

The results reported in Table 3, however, might be biased because we do not take into account the potential cyclical structure. Thus, based on the potential existence of unit roots in the two logged series, we next examine a model of the following form:

$$
\left(1-2 \cos w_{r} L+L^{2}\right)^{d} x_{t}=u_{t}, \quad t=1,2, \ldots,
$$

where $x_{\mathrm{t}}$ is now the first differenced series and where $w_{\mathrm{r}}=2 \pi \mathrm{r} / \mathrm{T}$ with $\mathrm{r}=\mathrm{T} / \mathrm{j}$, j indicates the number of periods per cycle and $\mathrm{r}$ the frequency with a singularity or pole in the spectrum.

Table 4 displays the results for the original (first differenced) and mean-subtracted data. They are similar in both cases. We observe that the values of $\mathrm{j}(101$ and 59 ) are very close to those observed in the periodograms of the first differenced data in Fig. 4, and the estimated values of $d$ are slightly positive though significantly differently from zero. The $\mathrm{j}$-values of 101 and 59 indicate that the cyclical structure repeat itself at approximately 7.52 (760/101) and 5.59 (330/59) years, being therefore higher for gold than for silver.

Furthermore, we extend that model to a more flexible one, where the order of integration at the long run frequency is not set up to be equal to 1 but estimated from the data along with the other parameters. In particular we consider the model,

$$
(1-L)^{d_{1}}\left(1-2 \cos w_{r} L+L^{2}\right)^{d_{2}} x_{t}=u_{t}, \quad t=1,2, \ldots
$$

Table 5 displays the results under the assumption of white noise errors. We observe that the values of $j$ now change slightly with respect to the previous cases, being now 103 and 101 for gold and 69 and 55 for silver. This implies that according to this specification the cycles have a periodicity around 7 years for gold and between 4 and 5 for silver. Moreover, the estimated value of $d_{1}$ is below 1 in the two series, being smaller for gold than for silver. On the other hand, the estimated values of $d_{2}$ are significantly negative in the two series. 
Table 6

Estimated coefficients in the model given by (10) under autocorrelated disturbances.

\begin{tabular}{llrl}
\hline (i) Original data & & & \\
\hline Series & $d_{1}$ & $\mathrm{j}$ & \multicolumn{1}{l}{$d_{2}$} \\
\hline Gold & $0.80(0.71,0.88)$ & 100 & $-0.28(-0.34,-0.14)$ \\
Silver & $0.70(0.64,0.78)$ & 60 & $-0.16(-0.27,-0.05)$ \\
\hline (ii) Mean subtracted data & & \\
\hline Series & $d_{1}$ & $\mathrm{j}$ & $d_{2}$ \\
\hline Gold & $0.77(0.66,0.83)$ & 101 & $-0.25(-0.33,-0.12)$ \\
Silver & $0.61(0.55,0.72)$ & 61 & $-0.08(-0.15,0.00)$ \\
\hline
\end{tabular}

Table 7

Structural breaks in the series.

\begin{tabular}{lll}
\hline Series & Number of breaks & Break dates \\
\hline Gold & 3 & $1545 ; 1696 ; 1903$ \\
Silver & 1 & 1950 \\
\hline
\end{tabular}

In Table 6 we assume that the errors are autocorrelated, and the results are quite similar in the sense that mean reversion is detected on the long run or zero frequency, and anti-persistence $(\mathrm{d}<0)$ for the cyclical (non-zero) frequency.

Finally, we conduct Bai and Perron's [61] tests for the existence of breaks. The results are reported in Table 7. We found three breaks for gold, at 1545, 1696 and 1903, and a single one for silver (1950). Identical breaks were obtained when using other approaches like Hassler and Meller [62] or Gil-Alana [63].

Table 8 focuses on the estimates of $d$ in Eq. (8) for each subsample in each of the series. As in Table 3, we report the results for the three cases of no regressors, an intercept, and an intercept with a linear time trend. We observe that for gold, the time trend is required in the first, the second and the fourth subsamples under the two cases of uncorrelated and autocorrelated errors. For silver, the time trend is only required in the second subsample under autocorrelation. If we focus now on the estimated values of $d$ we see that for gold, the I(1) hypothesis is only rejected in a single case, corresponding to the 3rd subsample in the case of no autocorrelation. In this case, $d$ is found to be significantly higher than 1 . For the remaining cases, the unit root null hypothesis cannot be rejected. For silver, the I(1) hypothesis cannot be rejected in any of the two subsamples under no autocorrelation. However, including autocorrelation, this hypothesis is rejected in the two subsamples in favor of mean reversion $(\mathrm{d}<1)$.

Next, we examine the model corresponding to Eq. (9), i.e., with a single pole at a non-zero frequency. The results, though not reported, show values of d very close to 0 in all subsamples, which is clearly due to the wider confidence bands as a consequence of the smaller sample sizes. Finally, we examine model (10), i.e., allowing for two poles, one corresponding to the long run or zero frequency, and another one for the cyclical component. Results are reported in Table 9. We only report the results for the case of white noise errors, though the same conclusions were obtained under autocorrelation. We observe that for gold, the estimates of $\mathrm{d} 2$ (cyclical persistence) are insignificantly different from zero in the four subsamples, once more due to the wide associated confidence intervals. The estimates of $\mathrm{d} 1$ (long run persistence) are all higher than 0 and smaller than 1 implying long memory and oscillating between 0.43 (1st subsample) and 0.55 (2nd and 3rd subsamples). For silver, $\mathrm{d} 2$ is significantly positive during the first subsample, but becomes insignificant during the second subsample due to the smaller number of observations during this subsample (67 versus 263 in the first one). The estimate of $d 1$ increases from 0.26 in the first subsample to 0.58 in the second one. Finally, and referring to j, the values implies cycles with a periodicity constrained once more between 4 and 7 periods in all cases.

\section{Conclusions}

This study examines the degree of persistence in the trend and cyclical patterns of gold and silver prices using annual data that covers a period of more than seven centuries for gold (1257-2016) and more than three centuries for silver prices (1687-2016), a period which includes many historical episodes that significantly impacted oil and silver prices. Within a fractional integration framework, we use a model that incorporates simultaneously two fractional differencing parameters, one at the long run or zero frequency and another one at a cyclical frequency, following Gil-Alana et al. [40].

The main results are the following. First, when the trend persistence of gold and silver prices are analyzed without taking into account the potential cyclical structure of the data, the results suggest that the fractional integration order of both gold and silver prices is above 1, implying persistence in the prices of these two precious metals, as in Gil-Alana et al. [39,40]. As surveyed previously in the paper, this result is in line with most of the previous literature, which concludes that gold and silver prices follow non-stationary processes, as in [16] or [36]. However, and once the cyclical differencing parameter is taken into account, mean reversion (fractional integration orders below 1 ) is detected in the long run trend of both gold and silver prices, in contrast with most of the previous literature, and implying that shocks to these variables will have transitory effect on the price of these two precious metals. Second, when we allow for structural breaks in both gold and silver prices 
Table 8

Estimates of the long run persistence parameter for each subsample.

\begin{tabular}{|c|c|c|c|}
\hline \multicolumn{4}{|l|}{ Gold } \\
\hline \multicolumn{4}{|c|}{ (i) No autocorrelation } \\
\hline Series & No terms & An intercept & A linear trend \\
\hline 1st subsample & $\begin{array}{l}0.88 \\
(0.81,0.97)\end{array}$ & $\begin{array}{l}0.91 \\
(0.83,1.01)\end{array}$ & $\begin{array}{l}0.91 \\
(0.84,1.01)\end{array}$ \\
\hline 2nd subsample & $\begin{array}{l}1.03 \\
(0.92,1.18)\end{array}$ & $\begin{array}{l}0.96 \\
(0.85,1.12)\end{array}$ & $\begin{array}{l}0.97 \\
(0.87,1.12)\end{array}$ \\
\hline 3rd subsample & $\begin{array}{l}0.98 \\
(0.89,1.09)\end{array}$ & $\begin{array}{l}1.19 \\
(1.04,1.37)\end{array}$ & $\begin{array}{l}1.19 \\
(1.04,1.38)\end{array}$ \\
\hline 4rd subsample & $\begin{array}{l}1.02 \\
(0.88,1.22)\end{array}$ & $\begin{array}{l}1.10 \\
(0.96,1.31)\end{array}$ & $\begin{array}{l}1.10 \\
(0.96,1.31)\end{array}$ \\
\hline \multicolumn{4}{|c|}{ (i) With autocorrelation } \\
\hline 1st subsample & $\begin{array}{l}0.89 \\
(0.77,1.09) \\
\end{array}$ & $\begin{array}{l}0.91 \\
(0.78,1.13) \\
\end{array}$ & $\begin{array}{l}0.93 \\
(0.78,1.12) \\
\end{array}$ \\
\hline 2nd subsample & $\begin{array}{l}0.91 \\
(0.74,1.14)\end{array}$ & $\begin{array}{l}0.98 \\
(0.83,1.23)\end{array}$ & $\begin{array}{l}0.98 \\
(0.80,1.21)\end{array}$ \\
\hline 3rd subsample & $\begin{array}{l}0.94 \\
(0.81,1.14)\end{array}$ & $\begin{array}{l}0.80 \\
(0.54,1.18)\end{array}$ & $\begin{array}{l}0.80 \\
(0.54,1.18)\end{array}$ \\
\hline 4rd subsample & $\begin{array}{l}0.78 \\
(0.66,1.02)\end{array}$ & $\begin{array}{l}0.86 \\
(0.75,1.08)\end{array}$ & $\begin{array}{l}0.79 \\
(0.59,1.09)\end{array}$ \\
\hline \multicolumn{4}{|l|}{ Silver } \\
\hline \multicolumn{4}{|c|}{ (i) No autocorrelation } \\
\hline Series & No terms & An intercept & A linear trend \\
\hline 1st subsample & $\begin{array}{l}0.96 \\
(0.86,1.09)\end{array}$ & $\begin{array}{l}1.03 \\
(0.92,1.15)\end{array}$ & $\begin{array}{l}1.03 \\
(0.92,1.15)\end{array}$ \\
\hline 2nd subsample & $\begin{array}{l}1.05 \\
(0.86,1.36) \\
\end{array}$ & $\begin{array}{l}1.05 \\
(0.88,1.40) \\
\end{array}$ & $\begin{array}{l}1.05 \\
(0.85,1.40) \\
\end{array}$ \\
\hline \multicolumn{4}{|c|}{ (i) With autocorrelation } \\
\hline 1st subsample & $\begin{array}{l}0.75 \\
(0.62,0.92)\end{array}$ & $\begin{array}{l}0.81 \\
(0.68,0.98)\end{array}$ & $\begin{array}{l}0.80 \\
(0.63,0.98)\end{array}$ \\
\hline 2nd subsample & $\begin{array}{l}0.62 \\
(0.41,0.94)\end{array}$ & $\begin{array}{l}0.64 \\
(0.50,0.88)\end{array}$ & $\begin{array}{l}0.46 \\
(0.17,0.83)\end{array}$ \\
\hline
\end{tabular}

Note: In bold the significant models according to the deterministic terms. In parenthesis, 95\% confidence intervals of the estimated values of $d$.

Table 9

Estimated coefficients in the model given by (10) under white noise disturbances.

\begin{tabular}{llll}
\hline Gold & & & \\
\hline Series & $d_{1}$ & $\mathrm{j}$ & $d_{2}$ \\
\hline 1st subsample & $0.43(0.31,0.49)$ & 55 & $0.02(-0.14,0.20)$ \\
2nd subsample & $0.55(0.25,0.70)$ & 25 & $0.09(-0.17,0.21)$ \\
3rd subsample & $0.55(0.43,0.63)$ & 47 & $0.17(-0.01,0.34)$ \\
4th subsample & $0.49(0.23,0.71)$ & 10 & $0.04(-0.19,0.24)$ \\
\hline Silver & & & \\
\hline Series & $d_{1}$ & $\mathrm{~J}$ & $d_{2}$ \\
\hline 1st subsample & $0.26(0.13,0.40)$ & 64 & $0.26(0.09,0.37)$ \\
2nd subsample & $0.58(0.46,0.81)$ & 15 & $-0.05(-0.17,0.32)$ \\
\hline
\end{tabular}

series (1545, 1696 and 1903 for gold; 1950 for silver prices), the results again suggest that without taking into account the potential cyclical structure of the data, the fractional integration order of both gold and silver prices is above 1 , while when the cyclical component is included, the fractional integration order of the series is below 1 , suggesting mean reversion of the series. Third, as far as the cyclical behavior of gold and silver prices is concerned, the null hypothesis of no cycles in the two series is rejected in favor of cyclical dependence, and we find that cycles have a higher periodicity for gold (around 7 years) than for silver ( $4-5$ years).

The mean-reverting behavior of real gold and silver prices will have several implications in a number of areas. For example, in the event of shocks, the effects will only be temporary on both gold and silver prices, and the two prices will return to their original trends. Furthermore, and as explained in the paper, we should consider this mean-reverting behavior 
of real gold and silver prices when studying the role of gold and silver as diversification and hedging tools, when analyzing their effectiveness as inflation hedges, or when testing the Prebisch-Singer hypothesis, among other cases.

\section{Acknowledgment}

Juncal Cunado gratefully acknowledges financial support from Ministerio de Economía y Competitividad (ECO201783183-R)

\section{References}

[1] L.H. Officer, S.H. Williamson, The price of gold, 1257-present. MeasuringWorth, 2018. (http://www.measuringworth.com/gold).

[2] A. Silvennoinen, S. Thorp, Financialization, crisis and commodity correlation dynamics, J. Int. Financ. Mark. Inst. Money 24 (2013) $42-65$.

[3] K. Tang, W. Xiong, Index investment and the financialization of commodities, Financ. Anal. J. 68 (2012) 6.

[4] M.C.K. Lau, S.A. Vigne, S. Wang, L. Yarovaya, Return spillovers between white precious metal ETFs: The role of oil, gold, and global equity, Int. Rev. Financ. Anal. 52 (2017) 316-332.

[5] C.B. Erb, C.R. Harvey, The strategic and tactical value of commodity futures, Financ. Anal. J. (2006) 69-97.

[6] V. Babalos, S. Stravoyiannis, R. Gupta, Do commodity investors herd? Evidence from a time-varying stochastic volatility model, Resour. Policy 46 (2015) 281-287.

[7] B.M. Lucey, S. Li, What precious metals act as safe havens, and when? Some US evidence, Appl. Econ. Lett. 22 (2015) 35-45.

[8] S. Li, B.M. Lucey, Reassessing the role of precious metals as safe havens: What colour is your haven and why? J. Commod. Mark. 7 (2017) 1-14.

[9] J.A. Batten, C. Ciner, B.M. Lucey, On the economic determinants of the gold-inflation relation, Resour. Policy 41 (2014) 101-108.

[10] G. Bampinas, T. Panagioditis, Are gold and silver a hedge against inflation? A two century perspective, Int. Rev. Financ. Anal. 41 (2015) $267-276$.

[11] T.H. Van Hoang, A. Lahiani, D. Heller, Is gold a hedge against inflation? New evidence from a nonlinear ADRL approach, Econ. Model. 54 (2016) 54-66.

[12] V. Fernandez, Influence in commodity markets: Measuring co-movement globally, Resour. Policy 45 (2015) 151-164.

[13] A. Sensoy, E. Hacihasanog, D.K. Nguyen, Dynamic convergence of commodity futures: Not all type of commodities are alike, Resour. Policy 44 (2015) $150-160$.

[14] S. Basak, A. Pavlova, A model of financialization of commodities, J. Finance 71 (2016) 1511-1556.

[15] International Monetary Fund, International Monetary Fund, World Economic Outlook, 2015.

[16] A. Ghoshray, A reexamination of trends in primary commodity prices, J. Dev. Econ. 95 (2011) 242-251.

[17] D. Winkelried, Unit roots in real primary commodity prices? A meta-analysis of the Grilli and Yang data set. Working Papers, Banco Central de Reserva del Perú, 2017.

[18] World Gold Council, World Gold Council, Gold in a multicurrency reserve system, 2015. (https://www.gold.org/research/gold-multicurrency-reservesystem).

[19] F. Capie, T.C. Mills, G. Wood, Gold as a hedge against the dollar, J. Int. Financ. Mark. Inst. Money 15 (2005) 343-352.

[20] L.A. Sjaastad, The price of gold and the exchange rates: once again, Resour. Policy 33 (2008) 118-124.

[21] K. Pukthuanthong, R. Roll, Gold and the dollar (and the euro, pound, and yen), J. Bank. Finance 35 (2011) 2070-2083.

[22] D.G. Baur, Explanatory mining for gold: contrasting evidence from simple and multiple regressions, Resour. Policy 36 (2011) $265-275$.

[23] J. Beckmann, R. Czudaj, Gold as an inflation hedge in a time-varying coefficient framework, N. Am. J. Econ. Finance 24 (2013) $208-222$.

[24] G.C. Aye, T. Chang, R. Gupta, Is gold an inflation-hedge? Evidence from an interrupted markov-switching cointegration model, Resour. Policy 48 (1) (2016) 77-84.

[25] G.C. Aye, H. Carcel, L.A. Gil-Alana, R. Gupta, Does gold act as a hedge against inflation in the UK? Evidence from a fractional cointegration approach over 1257 to 2016, Resour. Policy 54 (1) (2017) 53-57.

[26] J. Beckmann, T. Berger, R. Czudaj, Gold price dynamics and the role of uncertainty. Chemnitz Economic Papers No.6, 2017.

[27] D.G. Baur, B.M. Lucey, Is gold a hedge or a safe haven? An analysis of stocks, bonds and gold, Financ. Rev. 45 (2010) 217-229.

[28] A. Escribano, C.W. Granger, Investigating the relationship between gold and silver prices, J. Forecast. 17 (1988) 81-107.

[29] D.G. Baur, D. Tran, The long-run relationship of gold and silver and the influence of bubbles and financial crises, Empir. Econom. 47 (2014) $1525-1541$.

[30] V. Fernandez, Some facts of the platinum-group elements, Int. Rev. Financ. Anal. 52 (2017) 333-347.

[31] J.A. Batten, C. Ciner, B.M. Lucey, The macroeconomic determinants of volatility in precious metals markets, Resour. Policy 35 (2010) $65-71$.

[32] M. Balcilar, R. Gupta, C. Pierdzioch, Does uncertainty move the gold price? New evidence from a nonparametric causality-in-quantiles test, Resour. Policy 49 (2016) 74-80.

[33] P. Andreasson, S. Bekiros, D.K. Nguyen, G.S. Uddin, Impact of speculation and economic uncertainty on commodity markets, Int. Rev. Financ. Anal. 43 (2016) $115-127$.

[34] J. Reboredo, G. Uddin, Do financial stress and policy uncertainty have an impact on the energy and metals markets? A quantile regression approach, Int. Rev. Econ. Finance 43 (2016) 284-298.

[35] M. Joets, V. Mignon, T. Razafindrabe, Does the volatility of commodity prices reflect macroeconomic uncertainty? Energy Econ. 68 (2017) 313-326.

[36] P.K. Narayan, R. Liu, Are shocks to commodity prices persistent? Appl. Energy 88 (2011) 409-416.

[37] M. Arouri, S. Hammoudeh, A. Lahiani, D. Nguyen, Long memory and structural breaks in modeling the return and volatility dynamics of precious metals, Q. Rev. Econ. Finance 52 (2002) 207-218.

[38] B.K. Uludag, Z. Lkhamazhapov, Long memory and structural breaks in the returns and volatility of Gold: Evidence from Turnkey, Appl. Econ. 46 (2014) $3777-2787$.

[39] L.A. Gil-Alana, S. Chang, M. Balcilar, G.C. Aye, R. Gupta, Persistence of precious metal prices: A fractional integration approach with structural breaks, Resour. Policy 44 (2015) 57-64.

[40] L.A. Gil-Alana, G.C. Aye, R. Gupta, Trends and cycles in historical gold and silver prices, J. Int. Money Finance 58 (2015) 98-109.

[41] L.A. Gil-Alana, S.O. Yaya, O.O. Awe, Time series analysis of co-movements in the prices of gold and oil: Fractional cointegration approach, Resour. Policy 53 (2017) 117-124.

[42] D. Winkelried, Unit roots, flexible trends, and the Prebisch-Singer hypothesis, J. Dev. Econ. 132 (2018) 1-17.

[43] J. Lee, M. Strazicich, Minimum Lagrange multiplier unit root test with two structural breaks, Rev. Econ. Stat. 85 (2003) $1082-1089$.

[44] J. Lee, M. Strazicich, Minimum LM unit root test with one structural break, Department of Economics, Appalachian State University, 2004.

[45] A. Ghoshray, M. Kejriwal, M.E. Wohar, Breaks, trends and unit roots in commodity prices: a robust investigation, Stud. Nonlinear Dyn. Econom. 18 (1) (2014) $23-40$.

[46] D.I. Harvey, N.M. Kellard, J.B. Madsen, M.E. Wohar, The prebisch-singer hypothesis: Four centuries of evidence, Rev. Econ. Stat. 92 (2) (2010) 367-377.

[47] D.I. Harvey, N.M. Kellard, J.B. Madsen, M.E. Wohar, Long-run commodity prices, economic growth, and interest rates: 17 th century to the present day, World Dev. 89 (C) (2017) 57-70. 
[48] A.I. McLeod, K.W. Hipel, Preservation of the rescaled adjusted range. A reassessment of the Hurst phenomenon, Water Resour. Res. 14 (1978) $491-507$.

[49] H.L. Gray, N. Yhang, W.A. Woodward, On generalized fractional processes, J. Time Series Anal. 10 (1989) 233-257.

[50] H.L. Gray, N. Yhang, W.A. Woodward, On generalized fractional processes. A correction, J. Time Series Anal. 15 (1994) 561-562.

[51] J. Ahtola, G.C. Tiao, Distributions of least squares estimators of autoregressive parameters for a process with complex roots on the unit circle, J. Time Series Anal. 8 (1987) 1-14.

[52] J. Ahtola, G.C. Tiao, A note on asymptotic inference in autoregressive models with roots on the unit circle, J. Time Series Anal. 8 (1) (1987) 15-18.

[53] H.J. Bierens, Testing the unit root with drift hypothesis against nonlinear trend stationary with an application to the US price level and interest rate, J. Econometrics 81 (1997) 29-64.

[54] H. Bierens, Complex unit roots and business cycles: Are they real? Econometric Theory 17 (2001) 962-983.

[55] L.A. Gil-Alana, Testing stochastic cycles in macroeconomic time series, J. Time Series Anal. 22 (4) (2001) 411-430.

[56] F.J. DePenya, L.A. Gil-Alana, Testing of nonstationary cycles in financial time series data, Rev. Q. Financ. Account. 27 (2006) 47-65.

[57] R. Dahlhaus, Efficient parameter estimation for self-similar process, Ann. Statist. 17 (1989) 1749-1766.

[58] P.M. Robinson, Efficient tests of nonstationary hypotheses, J. Amer. Statist. Assoc. 89 (428) (1994) 1420-1437.

[59] W.A. Brock, W. Dechert, J.A Scheinkman, B. LeBaron, A test for independence based on the Correlation Dimension, Econ. Rev. 15 (1996) 197-235.

[60] P. Bloomfield, An exponential model in the spectrum of a scalar time series, Biometrika 60 (1973) 217-226.

[61] J. Bai, P. Perron, Computation and analysis of multiple structural change models, J. Appl. Econometrics 18 (2003) 1-22.

[62] U. Hassler, B. Meller, Detecting multiple breaks in long memory: The case of US inflation, Empir. Econom. 46 (2014) 653-680.

[63] L.A. Gil-Alana, Fractional integration and structural breaks at unknown periods of time, J. Time Series Anal. 29 (2008) $163-185$. 